\title{
Abrasive fluidized bed finishing to improve the fatigue behaviour of Ti6Al4V parts fabricated by electron beam melting
}

\author{
Eleonora Atzeni ${ }^{1} \cdot$ Gianluca Rubino $^{2} \cdot$ Alessandro Salmi $^{1} \cdot$ Federica Trovalusci $^{3}$
}

Received: 16 February 2020 / Accepted: 21 July 2020 / Published online: 14 August 2020

(C) The Author(s) 2020

\begin{abstract}
A study of the abrasive fluidized bed (AFB) finishing process was conducted to quantify the obtainable improvement of the fatigue behaviour of Ti6A14V parts produced by electron beam melting (EBM). Axial-symmetric EBM samples were rotated at high speed inside a fluidized bed of stainless-steel media. The effects of the treatment time and the rotational speed on morphological features and fatigue life of the EBM samples were investigated. Outcomes showed that the improvement in surface properties induced by the AFB finishing process determined an increase up to $50 \%$ in fatigue life and a shift of the $S-N$ curve.
\end{abstract}

Keywords Electron beam melting $\cdot$ Abrasive fluidized bed $\cdot$ Fatigue life $\cdot$ Finishing $\cdot$ Additive manufacturing $\cdot S$ - $N$ curve

\section{Introduction}

The high mechanical performance, resistance to corrosion, biocompatibility and low density of titanium alloys make them a key material for the industry [1]. Typical applications of titanium alloys are in the aerospace and marine sectors, taking advantage of the corrosion behaviour and the good strength-to-weight ratio; moreover, these alloys are also

\section{Highlights}

- The abrasive fluidized bed finishing process is applied for finishing Ti6A14V parts fabricated by electron beam melting.

- The effect of the treatment and the rotational speed on the morphological features and the fatigue life of parts fabricated by electron beam melting is investigated.

- The sample rotational speed is influential on the effectiveness of finishing and fatigue life of samples.

- After the abrasive fluidized bed finishing process an increase in fatigue life up to $50 \%$ was observed.

\section{Alessandro Salmi}

alessandro.salmi@polito.it

1 Department of Management and Production Engineering, Politecnico di Torino, Corso Duca degli Abruzzi 24, 10129 Torino, Italy

2 Department of Economics, Engineering, Society and Business Organization, Università della Tuscia, Largo dell'Università, 01100 Viterbo, Italy

3 Department of Enterprise Engineering, Università degli Studi di Roma "Tor Vergata", Via del Politecnico 1, 00133 Rome, Italy largely used in the medical field, where biocompatibility is a crucial aspect $[2,3]$. Among the production technologies, additive manufacturing (AM) techniques are of great interest, since they allow combining the titanium alloys properties with the ability of AM to produce complex net-shaped parts, reducing component weight, raw material and additional tooling [4]. Additive manufacturing (AM) technologies have the potential of adding flexibility to products, allowing for design freedom, and to the production process since AM can rapidly respond to variations in product mix or design. Adding flexibility in manufacturing is a crucial point at the production level since the market demand is even more mutable and the product lifetime shorter [5].

Laser powder bed fusion (L-PBF) and electron beam melting (EBM) have emerged as the leading metal-based AM technologies for industrial production for a wide variety of metallic alloys, including titanium alloys [6, 7]. A computeraided design (CAD) model is built up layer-by-layer in AM, regardless of the complexity of the model geometry. At each incremental step, the raw material is selectively melted by the energy source, a laser in L-PBF or an electron beam in EBM. EBM and L-PBF processes are anyway not competing; rather they offer different advantages for different types of applications [8]. EBM and L-PBF parts of identical material are characterized by significantly different microstructures and mechanical properties, and the surface topology and quality are also distinctive $[9,10]$. In general, finer geometrical details and smoother surfaces are obtained by L-PBF, whereas higher productivity, lower oxygen contamination and minimal 


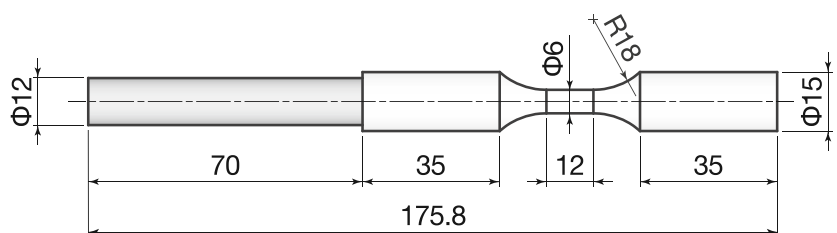

Fig. 1 Geometry of the fatigue test sample (all dimensions in $\mathrm{mm}$ )

residual stresses are characteristics of EBM. High residual stresses are typically developed in L-PBF components due to the high temperature gradients, while EBM parts are almost stress-free since the powder bed is maintained at elevated temperatures during all the building process [11-13]. Thus, stress relieving heat treatment that is required in L-PBF is avoided in EBM. Differently, after production EBM parts of titanium alloys may undergo hot isostatic pressing (HIP) treatment to further enhance mechanical properties, especially in terms of fatigue endurance, since internal voids or porosities that act as stress-concentrating areas are closed by the HIP process [14].

In EBM parts, the surface roughness is quite high, ranging from 10 to $40 \mu \mathrm{m}$. This is a characteristic of metal AM components, originated by the melting and solidification of the powder. In case the surface roughness is excessive, for some applications the AM parts might not comply with the requirements of mechanical design. The surface quality of the additive manufactured metal parts highly affects the fatigue behaviour. An increase in the roughness is detrimental to the fatigue life of a component, also when additively manufactured [15, 16]. The relation between the fatigue properties and the surface morphology is well established in the literature. In Nicoletto et al. [17], the influence of roughness and morphology of AM surfaces on the fatigue performances was quantified by performing fatigue tests on smooth specimens of titanium alloy, built along different orientations in the building volume. The study was conducted both on L-PBF and EBM specimens. The higher roughness of EBM parts led to a lower fatigue limit than L-PBF parts; however, the results showed a fairly isotropic fatigue behaviour of EBM specimens. Surface roughness can be reduced by EBM parameters' optimization or by an appropriate finishing process. Machining processes

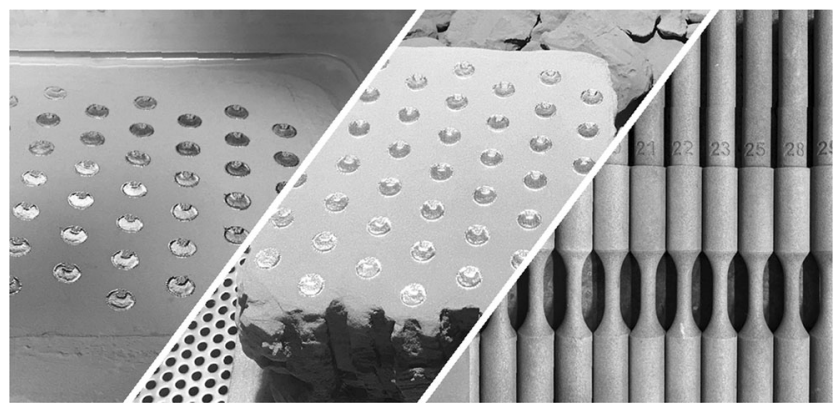

Fig. 2 Samples at the end of the fabrication phase inside the building chamber (last layer), during powder removal in the powder recovery system (PRS) and before finishing
Table 1 Main Ti6A14V EBM process parameters for Arcam EBM A2X system

\begin{tabular}{|c|c|c|c|}
\hline \multirow[t]{14}{*}{ Preheating $(50 \mu \mathrm{m})$} & \multirow[t]{7}{*}{ Preheat 1} & Line order & 15 \\
\hline & & Line offset & $1.2 \mathrm{~mm}$ \\
\hline & & Focus offset & $62 \mathrm{~mA}$ \\
\hline & & Hatch depth & $0.1 \mathrm{~mm}$ \\
\hline & & Max beam current & $30 \mathrm{~mA}$ \\
\hline & & Scan speed & $13,000 \mathrm{~mm} / \mathrm{s}$ \\
\hline & & Number of repetitions & 3 \\
\hline & \multirow[t]{7}{*}{ Preheat 2} & Line order & 15 \\
\hline & & Line offset & $1.2 \mathrm{~mm}$ \\
\hline & & Focus offset & $62 \mathrm{~mA}$ \\
\hline & & Hatch depth & $0.1 \mathrm{~mm}$ \\
\hline & & Max beam current & $38 \mathrm{~mA}$ \\
\hline & & Scan speed & $14,600 \mathrm{~mm} / \mathrm{s}$ \\
\hline & & Number of repetitions & 3 \\
\hline \multirow[t]{14}{*}{ Melting $(50 \mu \mathrm{m})$} & \multirow[t]{7}{*}{ Contour } & Scan speed & $850 \mathrm{~mm} / \mathrm{s}$ \\
\hline & & Focus offset & $6 \mathrm{~mA}$ \\
\hline & & Beam current & $5 \mathrm{~mA}$ \\
\hline & & Melting strategy & MultiBeam ${ }^{\mathrm{TM}}$ \\
\hline & & Number of spots & 70 \\
\hline & & Number of contours & 3 \\
\hline & & Hatch contours & $0.29 \mathrm{~mm}$ \\
\hline & \multirow[t]{7}{*}{ Hatching } & Speed function & 45 \\
\hline & & Focus offset & $25 \mathrm{~mA}$ \\
\hline & & Max beam current & $20 \mathrm{~mA}$ \\
\hline & & Melting strategy & Continuous \\
\hline & & Reference length & $45 \mathrm{~mm}$ \\
\hline & & Reference current & $12 \mathrm{~mA}$ \\
\hline & & Line offset & $0.20 \mathrm{~mm}$ \\
\hline
\end{tabular}

are commonly used to obtain good surface finish and close tolerances [18]. However, elaborated external surfaces and internal ones may not be easily accessible to machining tools, thus keeping the original as-built surface roughness. The resulting relatively poor fatigue strength is the most significant acceptability challenge of AM technology when considered for the production of net-shape parts, such as for loadbearing applications $[19,20]$. The attention has been thus recently paid on unconventional finishing processes that are an alternative to machining, suitable for AM parts [21].

Since the finish quality of additive manufactured metal components is still an issue, in this work a feasibility study of the abrasive fluidized bed (AFB) finishing process is proposed, to quantify what improvement of fatigue behaviour of Ti6Al4V parts produced by EBM can be obtained, if the surface roughness is reduced by AFB. AFB is a promising technology, based on the use of loose abrasives taken in a fluid state [22]. The fluidized abrasives surround the component as a liquid medium, and the complex surfaces that are typical of 
Fig. 3 Research process flowchart with process parameters

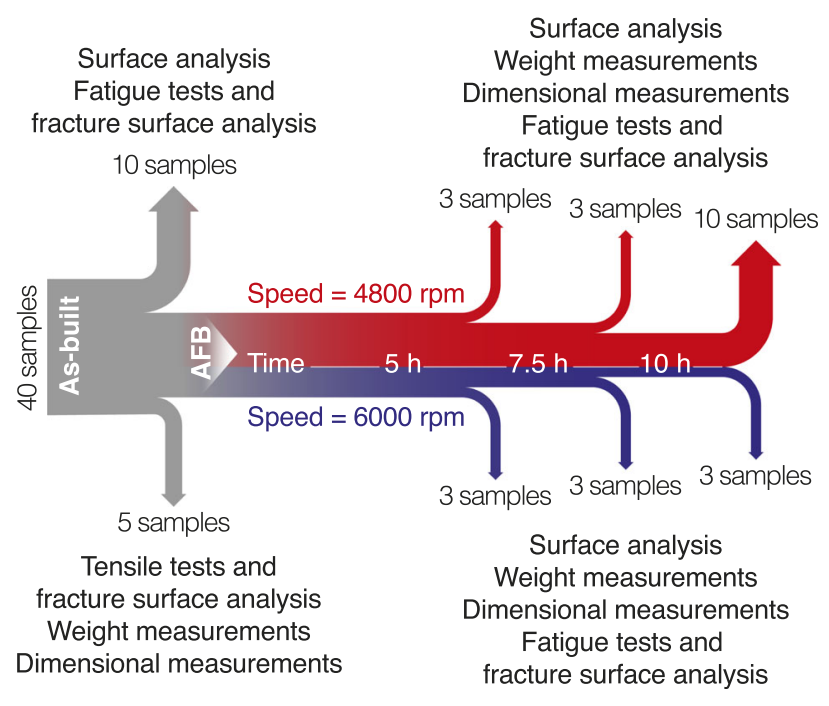

The effect of the treatment time $(5 \mathrm{~h}, 7.5 \mathrm{~h}$ and $10 \mathrm{~h})$ and of the sample rotational speed $(4800 \mathrm{rpm}$ and $6000 \mathrm{rpm}$ ) on morphological features and fatigue life was investigated. Modifications of the surface properties after AFB were related to the achieved improvements on the fatigue life.

\section{Materials and methods}

An axial-symmetric sample (Fig. 1) having basically the geometry of a fatigue test specimen was designed in order to systematically investigate the influence of AFB treatments on fatigue life of parts fabricated by EBM. The sample total length is $175.8 \mathrm{~mm}$ and consists of two parts. The right side in Fig. 1 represents the fatigue sample geometry according to the ISO 1143:2010 standard [26]; it is 105.8 in length, which includes the test zone of $12 \mathrm{~mm}$ long and $6 \mathrm{~mm}$ in diameter. The left side, in light grey colour in Fig. 1, is an additional cylindrical part, $70 \mathrm{~mm}$ long and $12 \mathrm{~mm}$ in diameter, that was used to clamp the sample in the AFB apparatus during the finishing treatment and was cut off immediately at the end of the finishing treatment.

Forty axial-symmetric samples in total were fabricated (Fig. 2). Samples were built using an Arcam EBM A2X system and Ti6A14V ELI (Grade 23) gas-atomized powder with a particle size distribution ranging from 45 to $105 \mu \mathrm{m}$, both supplied by Arcam EBM (Mölnlycke, Sweden). The layer thickness was $50 \mu \mathrm{m}$. All the building process was performed under vacuum. Before starting the building process, an initial pressure of $1 \cdot 10^{-5}$ mbar was obtained in the chamber. During the actual melting process, helium was introduced in the chamber with a controlled vacuum of $2 \cdot 10^{-3}$ mbar.

Fig. 4 a AFB apparatus and $\mathbf{b}$ a sample in the abrasive fluidized bed 
a)

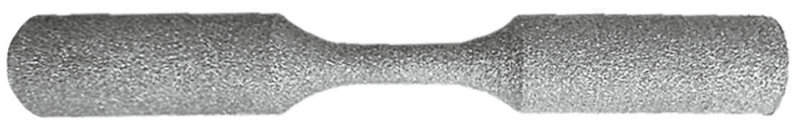

b)

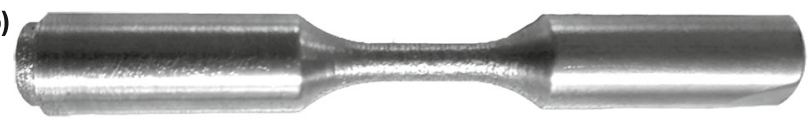

Fig. 5 a An as-built sample and $\mathbf{b}$ an AFB treated sample at $6000 \mathrm{rpm}$ for $10 \mathrm{~h}$

The fabrication of each layer consists of mainly four steps: powder spreading, dual-stage preheating, melting and postheating. During the preheating step, a defocused beam of electrons heats, up to $650{ }^{\circ} \mathrm{C}$, the freshly spread powder in order to partially consolidate the material. The preheating comprises two stages. In the first stage named preheat 1 , a light sinter of the new powder layer is performed on the bounding area that includes the cross-sections of all the parts, and then, in the second stage named preheat 2 , the preheated area is restricted to the regions corresponding to each part of the cross-sections in order to increase the local sintering of the powder. Then in the melting step, the powder is selectively melted according to the bi-dimensional crosssection computed during the slicing phase of the CAD data. Also, the melting step is performed in two stages, namely, contour and hatching. During the melting step, the EBM Control software evaluates the amount of energy transferred into the powder bed. A postheating stage is performed if the transferred energy is not enough to keep the temperature of the powder bed constant. In the postheating stage, the same parameters of preheat 1 are used. The standard sets (themes) of process parameters for Ti6Al4V were adopted [27]. In details, themes named Ti6Al4V A2X-PreHeat-50um5.0.61 and Ti6Al4V A2X-Melt-50um-5.0.61 were used for the preheating/postheating and melting steps respectively, and the relevant process parameters are listed in Table 1. The total build time was $3310 \min (55 \mathrm{~h}$ and $10 \mathrm{~min}$ ) including the processing time of $2911 \mathrm{~min}$ (48 $\mathrm{h}$ and $31 \mathrm{~min}$ ) and the final cooling down.

After additive manufacture, twenty-five samples were treated by AFB. As illustrated in the research flowchart of Fig. 3, the remaining fifteen samples were used to investigate the properties of the as-built AM material. The AFB apparatus includes an air supply system and a vertical fluidization column. The column is $500 \mathrm{~mm}$ in height and $100 \mathrm{~mm}$ in diameter (Fig. 4a). The abrasive media in the bed was uniformly fluidized through a porous plate distributor. The cylindrical part of the samples was clamped by a collet chuck, and the test geometry was kept in the inner part of the fluidization column (Fig. 4b). Samples were rotated to ensure process uniformity on the whole surface and exposed for different treatment times $(5 \mathrm{~h}, 7.5 \mathrm{~h}$ and $10 \mathrm{~h})$ to repeated impacts by the incoming stainless-steel powder (Type S, mesh size $12 \mu \mathrm{m}$, angular stainless-steel grit, $64 \mathrm{HRC}$ ). The powder was not replaced during experiments due to the long life of this abrasive media when used for Ti6Al4V finishing in AFB. To realize fast machining speed, the samples were rotated at high speed into the fluidized bed. Two rotating speeds were tested: $4800 \mathrm{rpm}$ and $6000 \mathrm{rpm}$. The minimum airflow, necessary to fluidize the abrasive particles, was supplied to establish a minimum fluidization regime as detailed in Kunii and Levenspiel [28]. The fluidizing gas (purified air) and the abrasive particles were both inert, and there were no reactions inside the fluidized bed.
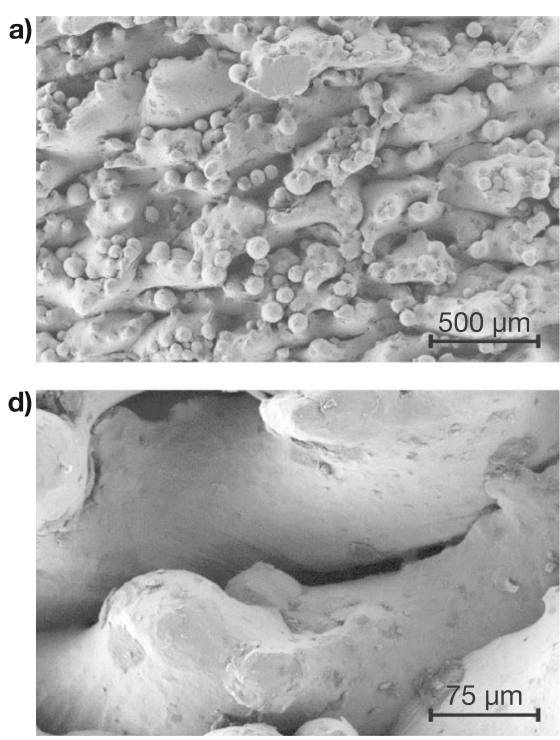

b)

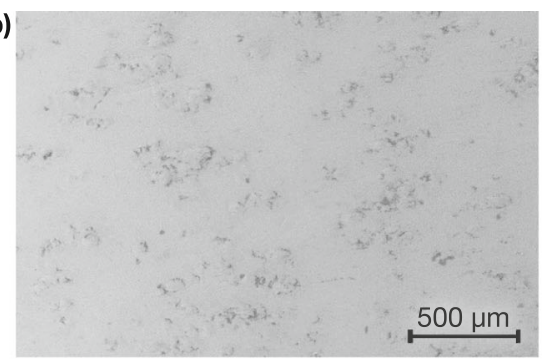

e)

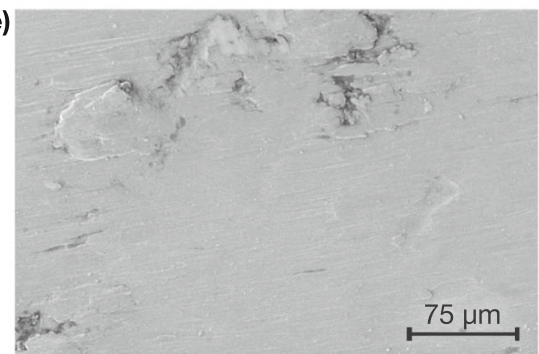

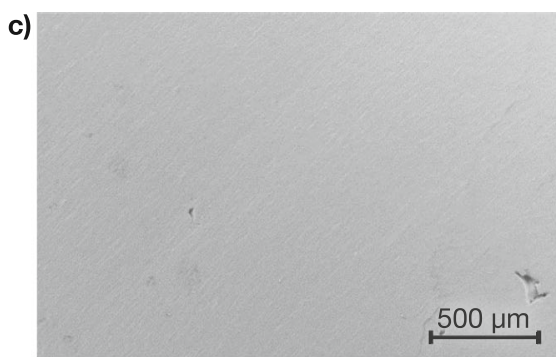

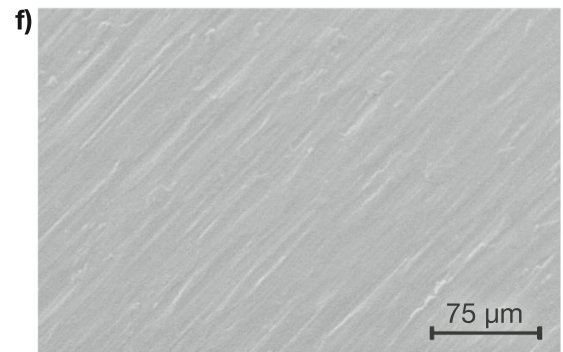

Fig. 6 SEM analysis of the external surfaces: a as-built and b AFB treated at $4800 \mathrm{rpm}$ for $10 \mathrm{~h}$ and $\mathbf{c}$ treated at $6000 \mathrm{rpm}$ for $10 \mathrm{~h}$ 
a)

As-built
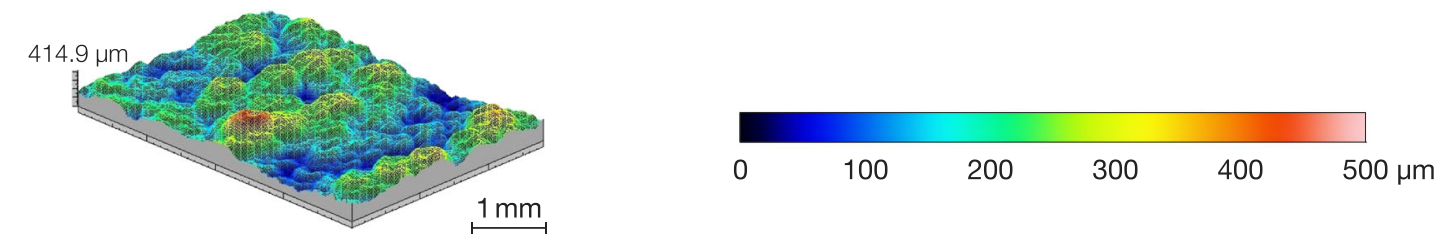

b)

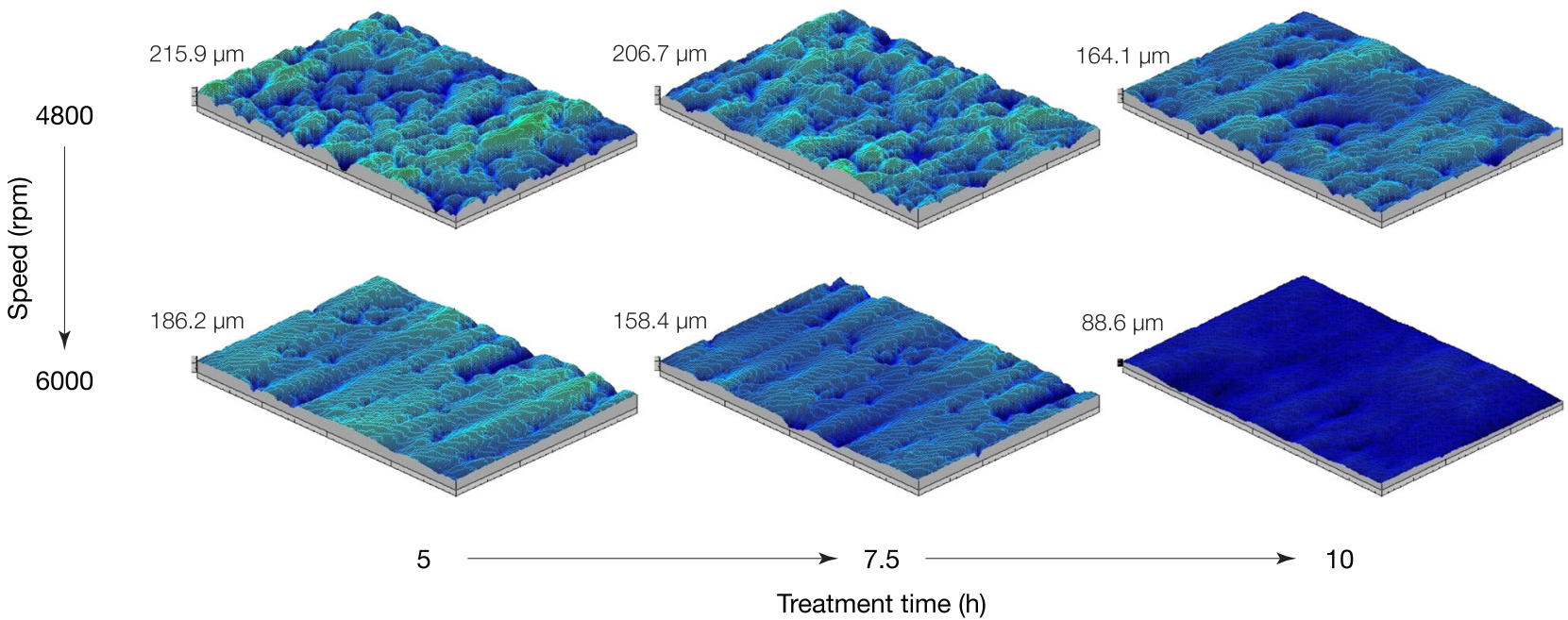

Fig. 7 Three-dimensional maps acquired by the profilometer: a as-built sample and $\mathbf{b}$ AFB treated samples at different process conditions

The morphology evolution caused by the interaction between the fluidized abrasives and the titanium samples was analysed by using a Leo SUPRA 35-FEG-SEM by Zeiss
(Thornwood, NY, USA) and by a Talysurf CLI 200 contact gauge profilometer by Taylor Hobson (Leicester, UK). Threedimensional maps, $3 \times 4 \mathrm{~mm}^{2}$, were acquired, with spacing
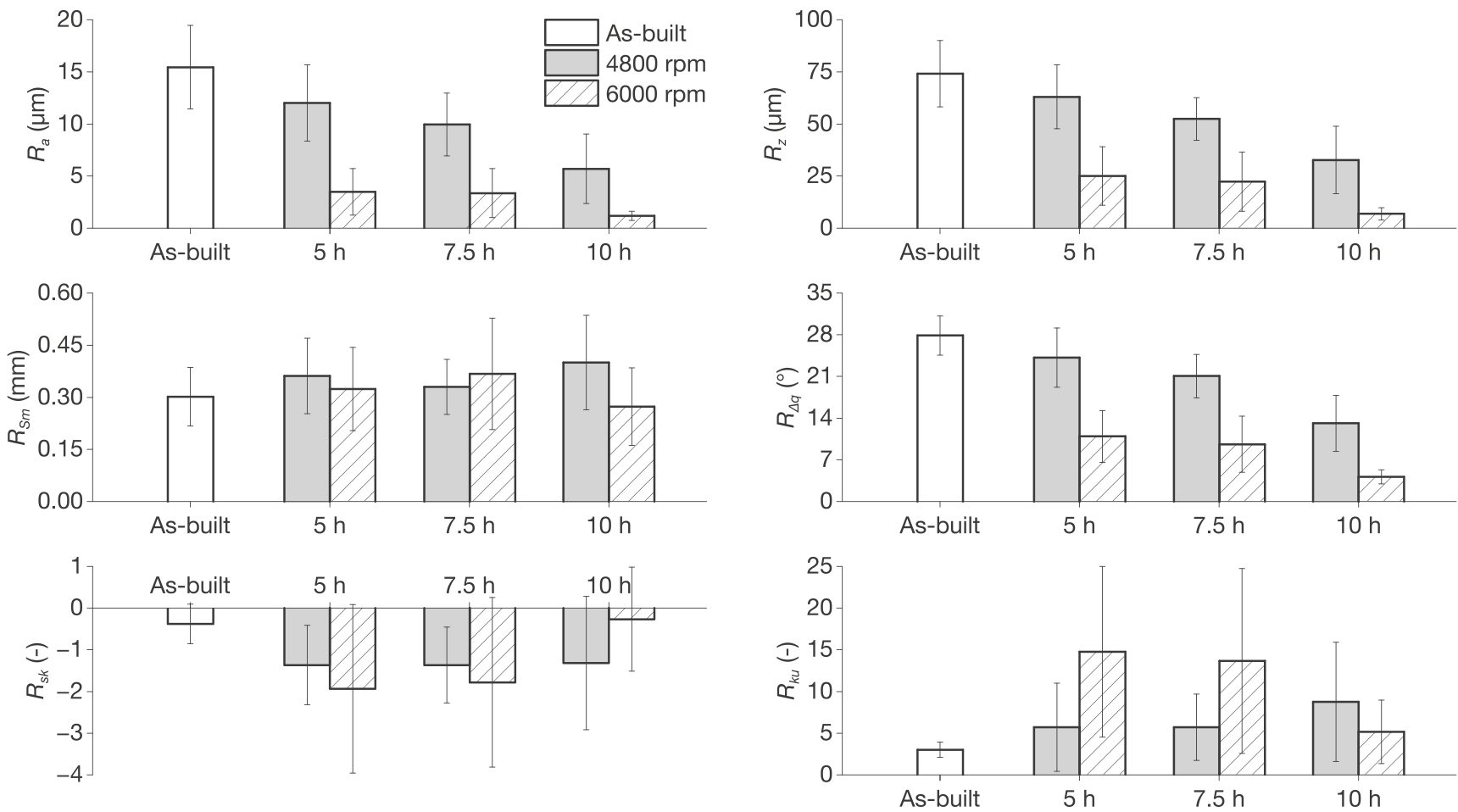

Fig. 8 Roughness parameters for as-build samples and treated samples after AFB treatment at different process conditions 
a)

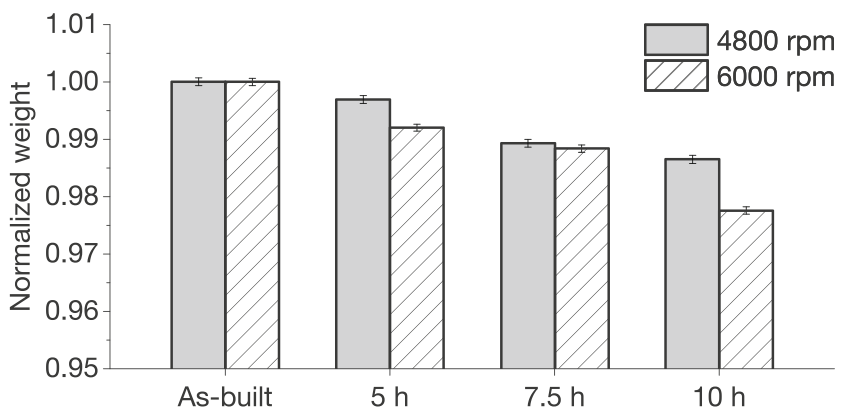

b)

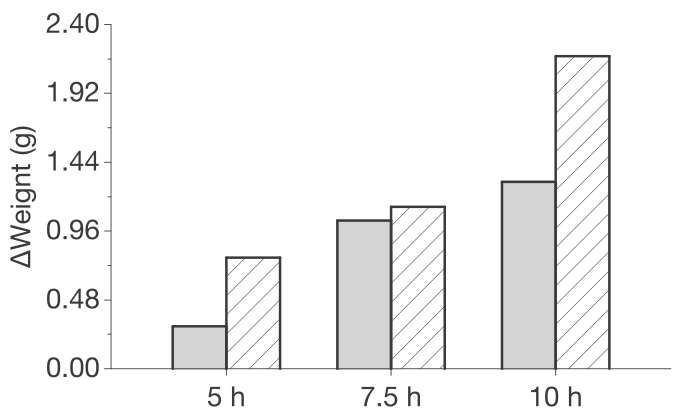

Fig. 9 a Normalized weights and $\mathbf{b}$ weight variations for as-built samples and treated samples after AFB treatment at different process conditions

$2 \mu \mathrm{m}$ and measurement speed $200 \mu \mathrm{m} / \mathrm{s}$. A Gaussian filter was adopted. Specifically, the surface morphology after finishing was captured by storing profiles along the longitudinal direction. Each profile was $7 \mathrm{~mm}$ long, the spacing $20 \mu \mathrm{m}$ and the measurement speed $500 \mu \mathrm{m} / \mathrm{s}$. All the bi-dimensional roughness parameters were evaluated with this approach. For each working condition, three repetitions of the test (processing and characterization) were performed in order to evaluate the average roughness parameters and standard deviations. Thus, the influence of the operational parameters, namely, treatment time and sample rotational speed, on the obtainable surface finish was assessed.

An MTS Alliance RT/100 universal testing machine by MTS Systems Corporation (Eden Prairie, MN, USA) equipped with MTS 634.12-5x extensometer, gage length $25 \mathrm{~mm}$ and travel $12.5 \mathrm{~mm}$ was used to perform the static tensile tests. Tensile tests are required in order to evaluate mechanical properties data that are needed for the subsequent fatigue tests.

The fatigue failure of as-built and treated samples was evaluated by adopting a rotating bending testing procedure. A 2 TM 831 rotating bending machine by Italsigma (Forlì, Italy) was used. Once fixed the load to $7.8 \mathrm{~kg}$, for each treatment condition, the number of cycles to failure, $N$, was determined. Thus, the condition beneficial to fatigue life was identified. For this condition and as-built samples, further fatigue tests were performed, and the load was varied to build the $S-N$ curves. Profilometry and SEM analyses allowed interpreting the improvement in the fatigue life observed on the treated samples.

\section{Result and discussion}

The results of the experimental campaign are presented in the following subsections, specifically describing the surface characteristics, the dimensional and mass change and the static and fatigue properties of the samples before and after AFB finishing.

\subsection{Surface analysis}

The morphology of the surfaces before and after treatment in the fluidized bed $(6000 \mathrm{rpm}$ for $10 \mathrm{~h}$ ) is shown in Fig. 5. The treated sample reflects the effective impact of the abrasive particles. The difference between the starting morphology and the one obtained after AFB treatment was strictly related to the setting of the rotational speed. SEM analysis allows evaluating the effect of increasing speed on the surface topography. A smoother morphology was obtained at the sample rotational speed of 6000 rpm (Fig. 6c). For both the adopted speed values, the AFB treatment determined the removal of partially molten powder agglomerates, typical of additively manufactured parts. The aspect of as-built surface in Fig. 6a was significantly a)

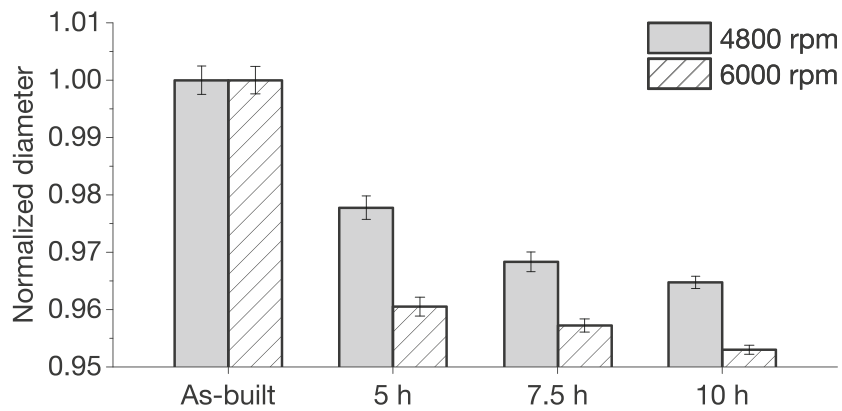

b)

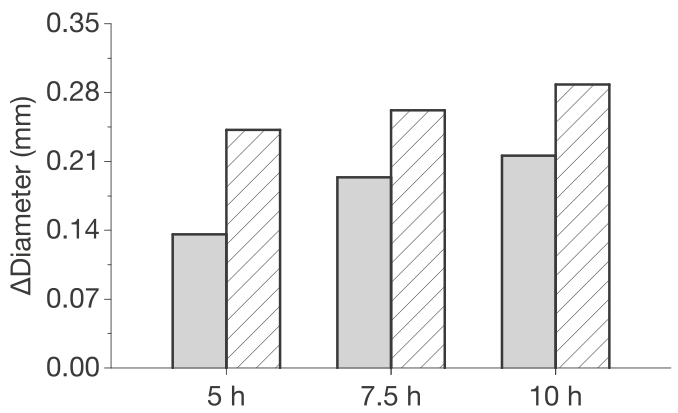

Fig. 10 a Normalized diameters and $\mathbf{b}$ diameter variations for as-built samples and treated samples after AFB treatment at different process conditions 


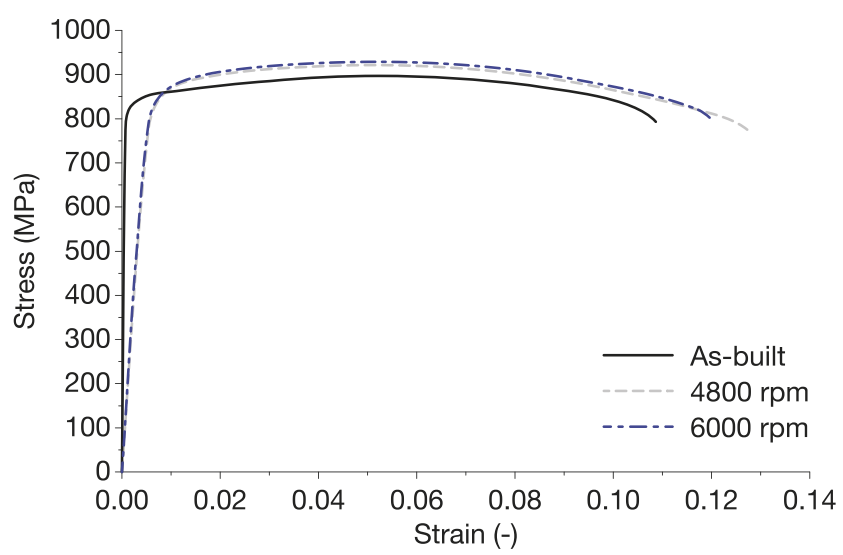

Fig. 11 Stress-strain curves for as-built samples and treated samples after AFB treatment at different sample rotational speeds (treatment time $10 \mathrm{~h}$ )

modified after the finishing process, and the starting agglomerates were completely flattened (Fig. $6 \mathrm{~b}$ and c).

Figure 7 shows the comparison of the three-dimensional maps acquired by the profilometer on the as-built sample and the treated ones at different AFB process conditions. The evolution of finishing is evident: With increasing treatment time and sample rotational speed, a smoother surface was progressively achieved. The AFB machining performed at $4800 \mathrm{rpm}$ determined higher values of roughness parameters than machining at $6000 \mathrm{rpm}$, for all the considered processing time. The best improvement in finishing was obtained by setting both speed and time at the highest considered value (6000 rpm and $10 \mathrm{~h}$ ): $R_{\mathrm{a}}$ lower than $1 \mu \mathrm{m}, R_{\mathrm{z}}$ around $5 \mu \mathrm{m}$ and $R_{\Delta \mathrm{q}}$ around $7^{\circ}$ were achieved. The sample finished at $6000 \mathrm{rpm}$ had a more regular morphology, with a homogeneous distribution of crests and valleys $\left(R_{\mathrm{sk}}\right)$, characterized by a variation of the slope $\left(R_{\Delta \mathrm{q}}\right)$ and by a reduced height $\left(R_{\mathrm{z}}\right)$.

To better analyse the morphology improvement, Fig. 8 displays the trend of roughness parameters versus AFB process conditions. As regards the effect of the sample rotational speed, lower values of $R_{\mathrm{a}}$ and $R_{\mathrm{z}}$ were always obtained when highspeed impacts between media and surface took place. An almost linear evolution of parameters with increasing time was found for the lower sample rotational speed (4800 rpm), while a significant variation of $R_{\mathrm{a}}$ and $R_{\mathrm{z}}$ was observed at higher sample rotational speed $(6000 \mathrm{rpm})$ after $10 \mathrm{~h}$ of treatment. Higher times were not considered because of the reduced industrial interest in longer processes. Moreover, the processing time considered in the present work is comparable with the duration of other treatments used to improve the fatigue life of titanium alloys [29]. The $R_{\mathrm{Sm}}$ spacing is about $0.3 \mathrm{~mm}$ in the as-built state and increases to about $0.4 \mathrm{~mm}$ after AFB finishing, confirming the flattening of the initial surface. The slope $R_{\Delta \mathrm{q}}$ that is about 28 in the as-built condition shows a slight decrease at the lower rotational speed, linear with the treatment time that indicates a slight smoothening of the surface. A sharp reduction to around 10 is noticed at the higher speed due to the higher contribution of the microcutting mechanisms that is confirmed by the larger amount of material removed (Fig. 9).

The hybrid parameters $R_{\mathrm{sk}}$ and $R_{\mathrm{ku}}$ of the samples treated at the lower speed are about -1.5 and 5 , respectively. The negative skewness is the evidence of an asymmetric roughness profile, being flattened the asperities protruding from the surface profile, and almost unaffected the valleys. The effect is more visible at the higher speed since microcutting effect is more significant in this process condition, and especially after $10 \mathrm{~h}$, the effectiveness of the AFB process is evident.

\subsection{Material removal mechanisms and dimensional analysis}

Microcutting occurred at a higher sample rotational speed; the resolidified metal droplets (Fig. 6a) were completely torn away by the impact of the abrasive (Fig. $6 \mathrm{~b}$ and c) as confirmed by the variation of sample weight in Fig. 9. A higher reduction of weight was found for the sample rotational speed of $6000 \mathrm{rpm}$. Accordingly, at higher magnifications of Fig. 6c, the microcutting grooves are clearly noticeable in the picture.

As Fig. 10 shows, the maximum variation of the diameter was $280 \mu \mathrm{m}$, much higher than $R_{\mathrm{z}}$, indicating that the entire outer layer, where the particles are partially melted, was removed during AFB processing.

\subsection{Yield stress and fractured surface after tensile test}

In order to collect the values of the yield stress of the material in as-built state and treated state, static tensile tests were executed. Figure 11 shows the stress-strain curves. The as-built samples showed an ultimate tensile stress of about $880 \mathrm{MPa}$, a yield stress of $830 \mathrm{MPa}$ and a strain to break of about $11 \%$. These values are in accordance with results in Liu and Shin [30] for EBM Ti6Al4V specimens in the as-built, not machined condition, even if the strain at break appears greater in this experimental campaign, indicating higher ductility. After AFB treatment, samples showed an ultimate tensile stress of about $920 \mathrm{MPa}$, a yield stress of $870 \mathrm{MPa}$ and a strain to break of $12 \%$, similar to typical values for EBM Ti6Al4V specimens in the as-built machined condition.

Figure 12 shows the fracture surface after the tensile test for as-built and AFB treated samples. The increase of strain to break, together with the decrease of the Young modulus, as depicted in Fig. 11, can be ascribed to the introduction of defects as a consequence of AFB treatment. In fact, at intermediate magnifications, cracks are clearly visible on the fracture surface after the tensile test in the case of the higher sample rotational speed $(6000 \mathrm{rpm})$ as shown in Fig. 12f. At higher magnifications, an intergranular fracture is also noted (Fig. 12i). During sample rotation, dynamic stress is generated and at higher speed (6000 rpm) led to a fatigue mechanism, as suggested by the smooth areas adjacent to the crack. 

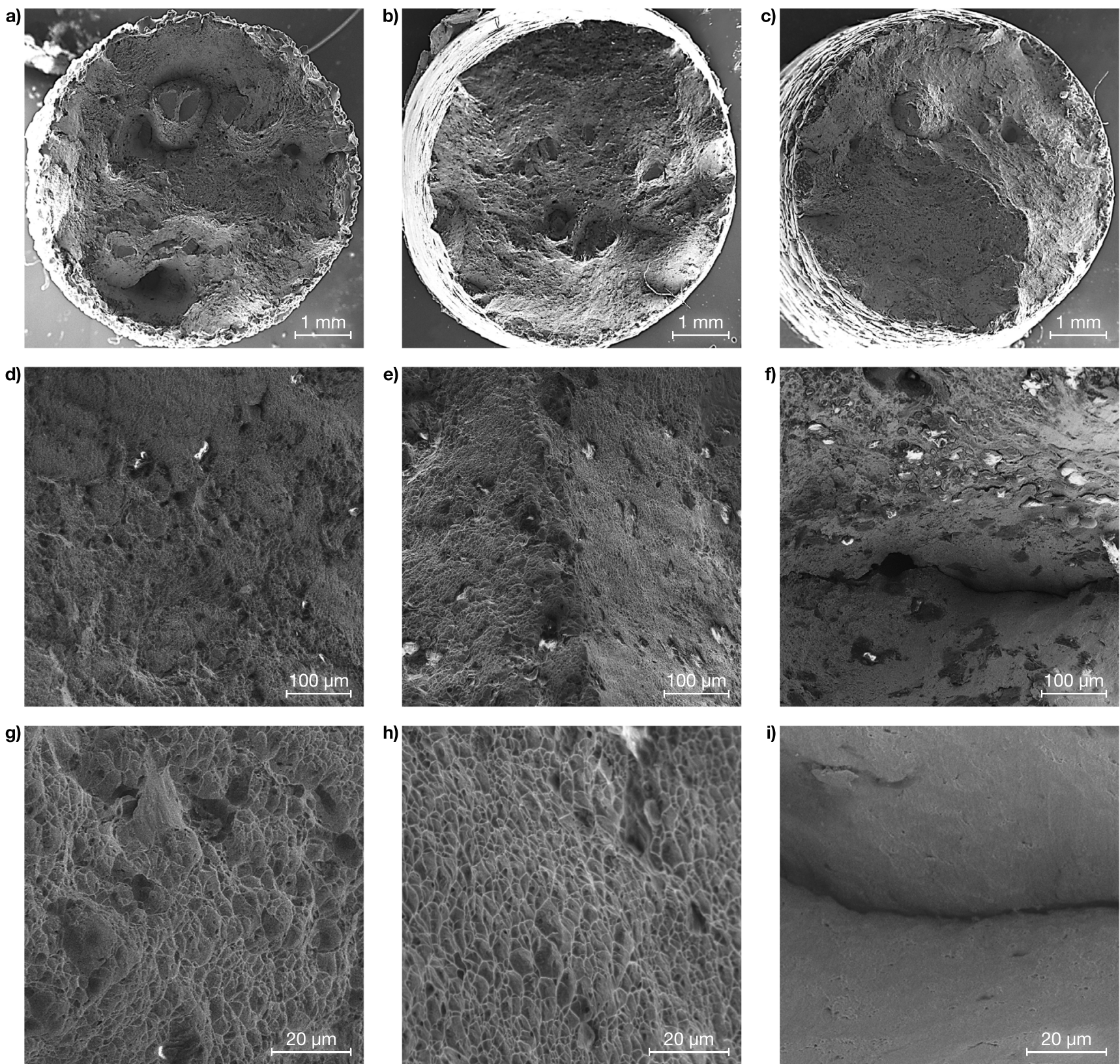

Fig. 12 Fracture surface after tensile tests: a, d, $\mathbf{g}$ as-built, $\mathbf{b}, \mathbf{e}, \mathbf{h}$ AFB treated at $4800 \mathrm{rpm}$ for $10 \mathrm{~h}$ and $\mathbf{c}, \mathbf{f}, \mathbf{i}$ AFB treated at $6000 \mathrm{rpm}$ for $10 \mathrm{~h}$

\subsection{Fatigue behaviour}

The number of cycles to failure of as-built and treated samples under repeated loading is detailed in Table 2. As-built samples were characterized without performing finishing and to have a

Table 2 Number of cycles to failure for a fixed load of $7.8 \mathrm{~kg}$

\begin{tabular}{ll}
\hline Sample condition & Number of cycles \\
\hline As-built & 41,950 \\
AFB at $4800 \mathrm{rpm}$ for $10 \mathrm{~h}$ & 74,191 \\
AFB at $6000 \mathrm{rpm}$ for $10 \mathrm{~h}$ & 25,397 \\
\hline
\end{tabular}

reference for comparison with treated samples. Inherent surface defects had a deleterious effect leading to poor fatigue performances, and samples failed after around $4.2 \cdot 10^{4}$ cycles at the applied stress of $240 \mathrm{MPa}$.

As shown in Fig. 13, the fatigue limit of the as-built samples appears consistent with similar results that are reported in Chern et al. [31] and Wang et al. [32] to be in the range of $100-200 \mathrm{MPa}(R=0.1,10 \mathrm{~Hz})$. In this study where the rotating bending fatigue tests were performed, this procedure is more affected by dynamic loads than push-pull tests. When the applied load is high, the contribution of the dynamic load is negligible, but for lower applied loads, a sudden decrease in the trend of Fig. 13 is visible. 


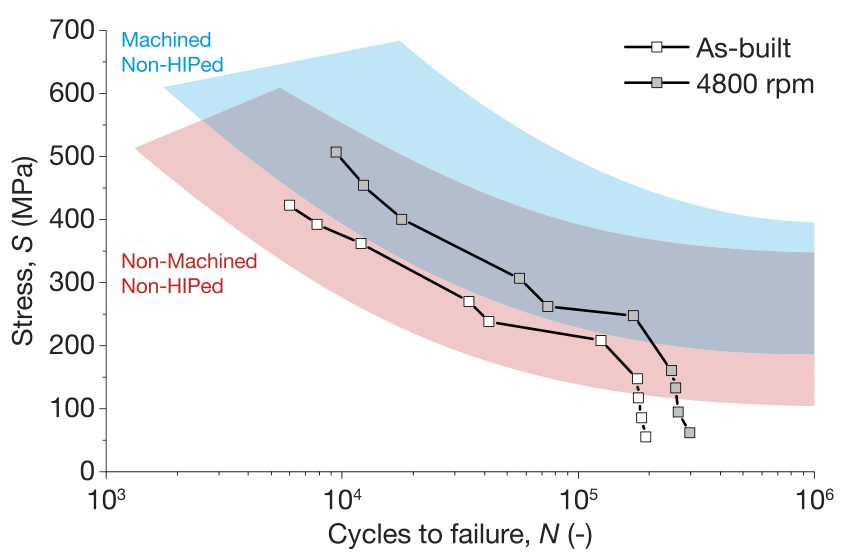

Fig. $13 S-N$ curve for as-built samples and treated samples (4800 rpm for $10 \mathrm{~h}$ ) and in the background typical fatigue ranges of non-HIPed machined and non-machined samples according to Chern et al. [31]

The AFB treatment led to an increase in fatigue life when the lower sample rotational speed was set. The increase by around $75 \%$ in the number of cycles to failure obtained at the sample rotational speed of $4800 \mathrm{rpm}$ is very significant. Figure 13 shows the shift of the $S-N$ curve after the AFB process, an improvement attributable to the better finishing which is expected to retard the crack nucleation. Contrarily, the sample rotational speed of $6000 \mathrm{rpm}$ was detrimental in terms of fatigue life, and a reduction of $39 \%$ in the fatigue life was observed. The two different responses were further investigated by analysing the fractured surfaces.

In Fig. 14 the fractured surfaces of the as-built and AFB treated samples are shown. In general, three main characteristics cause fatigue damage: a poor surface quality, the presence of porosities and defects and a tensile residual stress state. In EBM, however, the produced parts are almost stress-free, and the focus is thus on surface condition and microstructure. The inherent high roughness of the as-built surface acted as a stress concentration and surface irregularities caused crack initiation. In contrast, internal porosities and defects were more influential after finishing, and, by analysing the SEM images, it was observed that at the sample rotational speed of
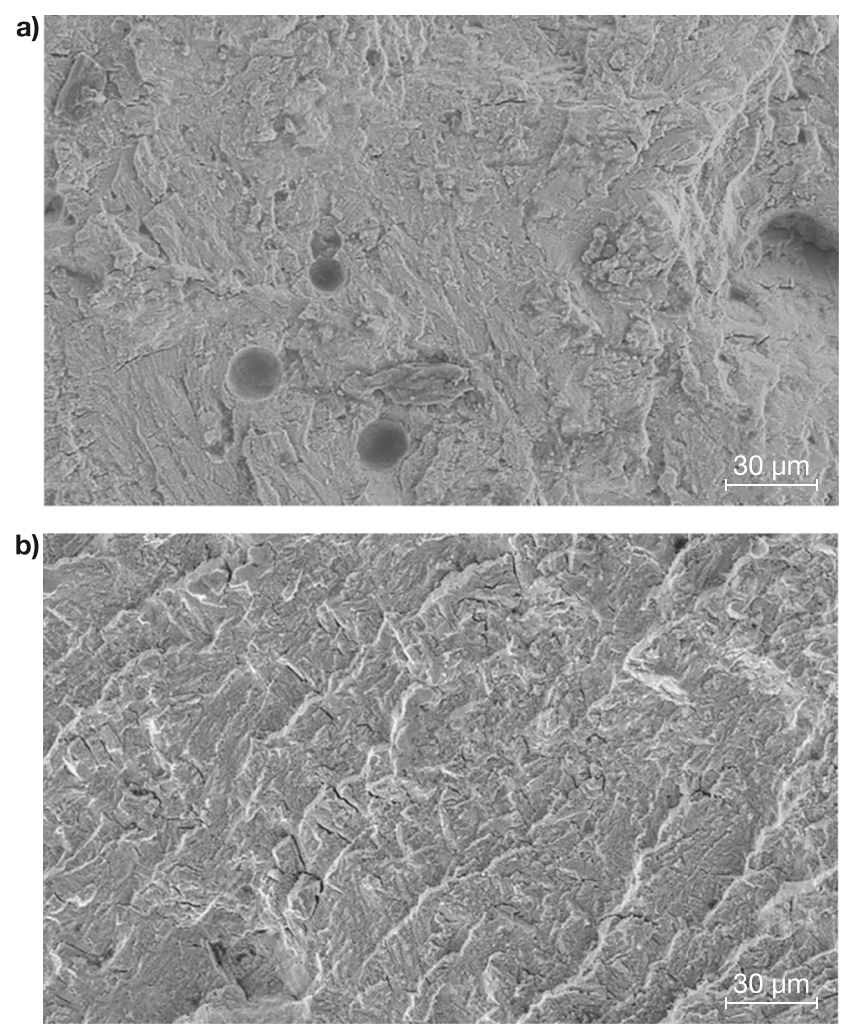

Fig. 15 SEM images of fracture surfaces after fatigue tests: a AFB treated at $4800 \mathrm{rpm}$ for $10 \mathrm{~h}$ and $\mathbf{b}$ AFB treated at $6000 \mathrm{rpm}$ for $10 \mathrm{~h}$

$4800 \mathrm{rpm}$, the brittle fracture occurred in the core of the cross-section [33]. Therefore, an improvement in fatigue behaviour was expected. On the contrary, for higher speed (6000 rpm), the crack initiated near the boundary.

The higher magnification in Fig. 15 shows the presence of subsurface cracks generated during the AFB process at the sample rotational speed of $6000 \mathrm{rpm}$, which determined a reduction of fatigue life. By analysing the cross-section of the sample rotated at $6000 \mathrm{rpm}$, more defects were evident, stating that during the high-speed treatment, dynamic loads were generated and resulted in crack initiation. a)

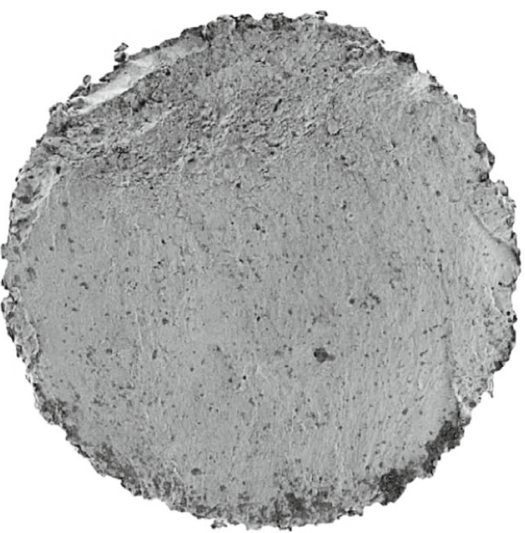

b)

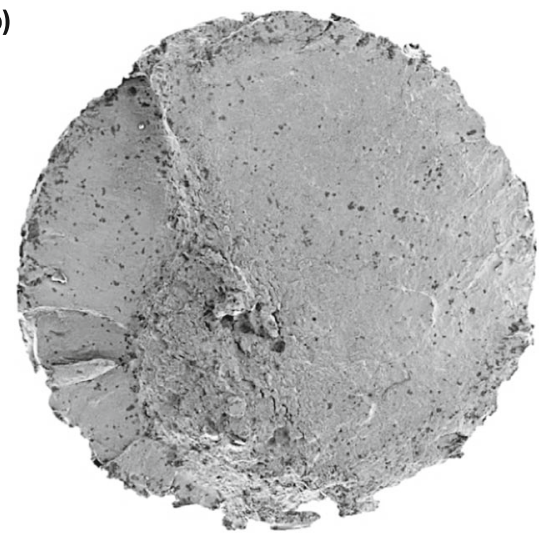

c)

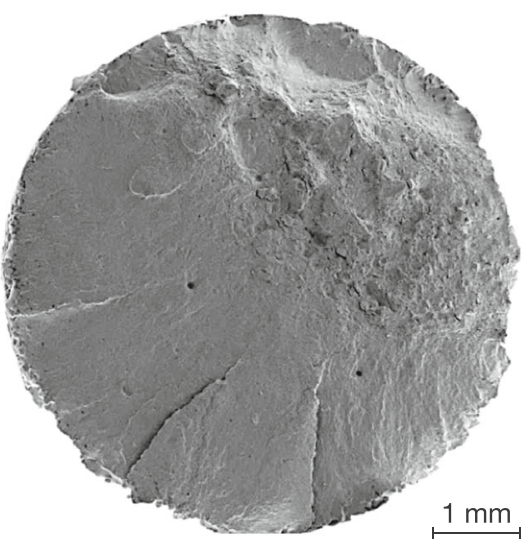

Fig. 14 Fractured surfaces after fatigue tests: a as-built, b AFB treated at $4800 \mathrm{rpm}$ for $10 \mathrm{~h}$ and $\mathbf{c}$ AFB treated at $6000 \mathrm{rpm}$ for $10 \mathrm{~h}$ 
If compared with shot peening, which could determine improvements of fatigue limits of metal peened surfaces, AFB has many advantages. Even if an enhancement by four times in the number of cycles was obtained by Okura et al. [34] when Ti6Al4V parts were subjected to shot-peening treatment, this is a high-pressure process with drawbacks related to safety, control, running costs and environmental impact. Contrarily, AFB treatment is performed at low pressure, can be easily controlled, does not require specific caution for safety and respect of environmental impact, can be scaled and can be completely automated without expensive procedures [22]. But more than this, the AFB process can also be applied for complex geometries, typical of AM [23]. Therefore, based on the discussed experimental results, it was found to be a promising technique to improve at the same time finishing and fatigue behaviour of additively manufactured parts, once fixed the appropriate process conditions, i.e. the optimum sample rotational speed inside the AFB. When the AFB process is optimized, the crack initiation during fatigue tests was retarded, being the treated surface smoother and defective-free.

\section{Conclusions}

Finishing of electron beam melting (EBM) additively manufactured Ti6Al4V samples was performed by rotating them inside an abrasive fluidized bed (AFB). The treatment was found to improve the finishing and, for appropriate AFB process conditions, the fatigue behaviour of samples. The sample rotational speed was influential on the effectiveness of finishing and fatigue life of samples. From this study some relevant conclusions can be drawn as follows:

- The typical morphology of surfaces obtained by AM was completely modified by the high-speed impact between media and surface. The microcutting mechanism removed the irregular outer layer, and a smoother morphology was found. The surface roughness reduction was linear with the treatment time when the sample was rotated at $4800 \mathrm{rpm}$, and the final average roughness was about $5 \mu \mathrm{m}$. The smoothening effect was amplified by increasing the sample rotational speed to $6000 \mathrm{rpm}$, with $R_{\mathrm{a}}$ equal to $1 \mu \mathrm{m}$.

- The increase of speed inside AFB was not beneficial in terms of fatigue life. By performing rotating bending tests, the number of cycles to failure was increased by $75 \%$ when the sample rotational speed inside the AFB was set at $4800 \mathrm{rpm}$, while a higher sample rotational speed, $6000 \mathrm{rpm}$, was detrimental to fatigue life, due to the generation of dynamic stresses near the surface.

- Once fixed the appropriate sample rotational speed inside the AFB, the crack initiation during fatigue tests was retarded due to the smoother and defective-free surface of treated surfaces. As a consequence in the fatigue test, the failure was not caused by surface cracks, as happened in as-built components, and internal defects were responsible for crack initiation and propagation. The $S-N$ curve was translated to larger values of the number of cycles.

These promising results encourage the study of the AFB process for finishing AM components. Additional treatment as the hot isostatic pressing (HIP) could improve the fatigue behaviour by closing internal pores. Thus, the combination of AFB finishing and HIP may be a viable solution for the complex geometries of AM parts. Further works include the optimization of the combination of process parameters to enhance the productivity and the evaluation of the repeatability of the finishing process.

Funding information Open access funding was provided by Politecnico di Torino within the CRUI-CARE Agreement. This research was partially supported by resources provided by the Interdepartmental Centre for Integrated Additive Manufacturing IAM@PoliTo at the Politecnico di Torino, Torino, Italy.

Open Access This article is licensed under a Creative Commons Attribution 4.0 International License, which permits use, sharing, adaptation, distribution and reproduction in any medium or format, as long as you give appropriate credit to the original author(s) and the source, provide a link to the Creative Commons licence, and indicate if changes were made. The images or other third party material in this article are included in the article's Creative Commons licence, unless indicated otherwise in a credit line to the material. If material is not included in the article's Creative Commons licence and your intended use is not permitted by statutory regulation or exceeds the permitted use, you will need to obtain permission directly from the copyright holder. To view a copy of this licence, visit http://creativecommons.org/licenses/by/4.0/.

\section{References}

1. Qian M, Bourell DL (2017) Additive manufacturing of titanium alloys. Jom 69(12):2677-2678. https://doi.org/10.1007/s11837017-2630-1

2. Hao Y-L, Li S-J, Yang R (2016) Biomedical titanium alloys and their additive manufacturing. Rare Metals 35(9):661-671. https:// doi.org/10.1007/s12598-016-0793-5

3. Baudana G, Biamino S, Klöden B, Kirchner A, Weißgärber T, Kieback B, Pavese M, Ugues D, Fino P, Badini C (2016) Electron beam melting of Ti-48Al-2Nb-0.7Cr-0.3Si: feasibility investigation. Intermetallics 73:43-49. https://doi.org/10.1016/j.intermet.2016.03.001

4. Froes FH (2018) Additive manufacturing of titanium components: an up-date. Metal Powder Report 73(6):329-337. https://doi.org/ 10.1016/j.mprp.2018.10.001

5. Eyers DR, Potter AT, Gosling J, Naim MM (2018) The flexibility of industrial additive manufacturing systems. Int J Oper Prod Manag 38(12):2313-2343. https://doi.org/10.1108/ijopm-042016-0200

6. Galba M, Reischle T (2015) Additive manufacturing of metals using powder-based technology. In: Additive Manufacturing, pp 97-142. https://doi.org/10.1201/b18893-5

7. Salmi A, Calignano F, Galati M, Atzeni E (2018) An integrated design methodology for components produced by laser powder bed 
fusion (L-PBF) process. Virtual Phys Prototyping 13(3):191-202. https://doi.org/10.1080/17452759.2018.1442229

8. Williams S, Martina F, Wood D, Garcia Colomo A (2020) A comparison framework to support the selection of the best additive manufacturing process for specific aerospace applications. Int $\mathrm{J}$ Rapid Manuf 9(3):1. https://doi.org/10.1504/ijrapidm.2020. 10019230

9. Lewandowski JJ, Seifi M (2016) Metal additive manufacturing: a review of mechanical properties. Annu Rev Mater Res 46(1):151186. https://doi.org/10.1146/annurev-matsci-070115-032024

10. Li P, Warner DH, Fatemi A, Phan N (2016) Critical assessment of the fatigue performance of additively manufactured $\mathrm{Ti}-6 \mathrm{Al}-4 \mathrm{~V}$ and perspective for future research. Int J Fatigue 85:130-143. https:// doi.org/10.1016/j.ijfatigue.2015.12.003

11. Salmi A, Atzeni E (2017) History of residual stresses during the production phases of AlSi10Mg parts processed by powder bed additive manufacturing technology. Virtual Phys Prototyping 12(2):153-160. https://doi.org/10.1080/17452759.2017.1310439

12. Salmi A, Atzeni E, Iuliano L, Galati M (2017) Experimental analysis of residual stresses on AlSi10Mg parts produced by means of selective laser melting (SLM). Procedia CIRP 62:458-463. https:// doi.org/10.1016/j.procir.2016.06.030

13. Salmi A, Piscopo G, Atzeni E, Minetola P, Iuliano L (2018) On the effect of part orientation on stress distribution in AlSi10Mg specimens fabricated by laser powder bed fusion (L-PBF). Procedia CIRP 67:191-196. https://doi.org/10.1016/j.procir.2017.12.198

14. Hrabe N, Gnäupel-Herold T, Quinn T (2017) Fatigue properties of a titanium alloy (Ti-6Al-4V) fabricated via electron beam melting (EBM): effects of internal defects and residual stress. Int J Fatigue 94:202-210. https://doi.org/10.1016/j.ijfatigue.2016.04.022

15. Greitemeier D, Dalle Donne C, Syassen F, Eufinger J, Melz T (2016) Effect of surface roughness on fatigue performance of additive manufactured Ti-6Al-4V. Mater Sci Technol 32(7):629-634. https://doi.org/10.1179/1743284715y.0000000053

16. Bagehorn S, Wehr J, Maier HJ (2017) Application of mechanical surface finishing processes for roughness reduction and fatigue improvement of additively manufactured Ti-6Al-4V parts. Int J Fatigue 102: 135-142. https://doi.org/10.1016/j.ijfatigue.2017.05.008

17. Nicoletto G, Konečná R, Frkáň M, Riva E (2018) Surface roughness and directional fatigue behavior of as-built EBM and DMLS Ti6Al4V. Int J Fatigue 116:140-148. https://doi.org/10.1016/j. ijfatigue.2018.06.011

18. Gok A (2015) A new approach to minimization of the surface roughness and cutting force via fuzzy TOPSIS, multi-objective grey design and RSA. Measurement 70:100-109. https://doi.org/ 10.1016/j.measurement.2015.03.037

19. Mower TM, Long MJ (2016) Mechanical behavior of additive manufactured, powder-bed laser-fused materials. Mater Sci Eng A 651:198-213. https://doi.org/10.1016/j.msea.2015.10.068

20. Kahlin M, Ansell H, Moverare JJ (2017) Fatigue behaviour of additive manufactured Ti6A14V, with as-built surfaces, exposed to variable amplitude loading. Int J Fatigue 103:353-362. https:// doi.org/10.1016/j.ijfatigue.2017.06.023

21. Atzeni E, Balestrucci A, Catalano AR, Iuliano L, Priarone PC, Salmi A, Settineri L (2020) Performance assessment of a vibro-finishing technology for additively manufactured components. Procedia CIRP 88: 427-432. https://doi.org/10.1016/j.procir.2020.05.074
22. Barletta M (2009) Progress in abrasive fluidized bed machining. J Mater Process Technol 209(20):6087-6102. https://doi.org/10. 1016/j.jmatprotec.2009.04.009

23. Atzeni E, Barletta M, Calignano F, Iuliano L, Rubino G, Tagliaferri V (2016) Abrasive fluidized bed (AFB) finishing of AlSil0Mg substrates manufactured by direct metal laser sintering (DMLS). Additive Manufacturing 10:15-23. https://doi.org/10.1016/j. addma.2016.01.005

24. Pietrobono F, Rubino G, Tagliaferri V, Trovalusci F (2019) Sample position inside abrasive fluidized bed to obtain morphology uniformity. Int J Adv Manuf Technol 103(1-4):49-61. https://doi.org/10. 1007/s00170-019-03539-y

25. Ribezzo A, Calignano F, Salmi A, Atzeni E, Pietrobono F, Trovalusci F, Rubino G (2018) Finishing of metal additive manufactured parts by abrasive fluidized bed machining. In: European Society for Precision Engineering and Nanotechnology, Conference Proceedings - 18th International Conference and Exhibition, EUSPEN 2018, pp 271-272

26. International Organization for Standardization ISO (2010) ISO 1143: 2010, Metallic materials - Rotating bar bending fatigue testing

27. Galati M, Minetola P, Rizza G (2019) Surface roughness characterisation and analysis of the electron beam melting (EBM) process. Materials 12(13). https://doi.org/10.3390/ma12132211

28. Kunii D, Levenspiel O (1991) Fluidization and mapping of regimes. In: Fluidization engineering. Butterworth-Heinemann, Stoneham, pp 61-94. https://doi.org/10.1016/b978-0-08-0506647.50009-3

29. Benedetti M, Cazzolli M, Fontanari V, Leoni M (2016) Fatigue limit of Ti6A14V alloy produced by selective laser sintering. Procedia Structural Integrity 2:3158-3167. https://doi.org/10. 1016/j.prostr.2016.06.394

30. Liu S, Shin YC (2019) Additive manufacturing of Ti6Al4V alloy: a review. Mater Des 164:107552. https://doi.org/10.1016/j.matdes. 2018.107552

31. Chern AH, Nandwana P, Yuan T, Kirka MM, Dehoff RR, Liaw PK, Duty CE (2019) A review on the fatigue behavior of Ti-6Al-4V fabricated by electron beam melting additive manufacturing. Int $\mathrm{J}$ Fatigue 119:173-184. https://doi.org/10.1016/j.jifatigue.2018.09.022

32. Wang L, Li S, Yan M, Cheng Y, Hou W, Wang Y, Ai S, Yang R, Dai K (2020) Fatigue properties of titanium alloy custom short stems fabricated by electron beam melting. J Mater Sci Technol 52:180-188. https://doi.org/10.1016/j.jmst.2020.02.047

33. Sun YY, Lu SL, Gulizia S, Oh CH, Fraser D, Leary M, Qian M (2020) Fatigue performance of additively manufactured Ti-6Al-4V: surface condition vs. internal defects. Jom 72(3):1022-1030. https://doi.org/10.1007/s11837-020-04025-7

34. Okura Y, Sasaki H, Soyama H (2020) Effect of mechanical properties on fatigue life enhancement of additive manufactured titanium alloy treated by various peening methods. In: Advanced Surface Enhancement. Lecture Notes in Mechanical Engineering, pp 8896. https://doi.org/10.1007/978-981-15-0054-1_10

Publisher's note Springer Nature remains neutral with regard to jurisdictional claims in published maps and institutional affiliations. 